\title{
SUSTENTABILIDADE E CONFORTO: A APLICAÇÃO DO TELHADO VERDE COMO SOLUÇÃO SUSTENTAVEL
}

\section{SUSTAINABILITY AND COMFORT: THE APPLICATION OF THE GREEN ROOF AS A SUSTAINABLE SOLUTION}

\section{Vinicius Luis Arcangelo Silva, Pós-Graduando (FAAG) Larissa Kashiwa (UNIP)}

\author{
Palavras Chave \\ Sustentabilidade; Telhado Verde; Arquitetura Sustentável
}

\section{Key Words}

Sustainability; Green Roof; Sustainable Architecture

\section{RESUMO}

A pesquisa apresentada tem por objetivo apresentar a elaboração do projeto de um protótipo para abrigo de animais domésticos (cachorro) de grande porte. Consideramos a necessidade física dos animais, comparados a nós, seres humanos, em questões de conforto ambiental, possibilitando melhorias e adaptações no projeto. Em primeiro plano inicia-se um estudo e levantamento de materiais e técnicas sustentáveis que tornem o projeto o mais sustentável e exequível. Adotamos a utilização de alguns materiais específicos e aliamos a técnicas sustentáveis como a implantação de um telhado verde e estudo de ventilação e iluminação, melhorando o conforto do usuário e tornando-o sustentável. Concluímos o projeto final para execução da casinha sustentável, utilizando para sua construção materiais como placas sustentáveis (material de reciclagem compensado), madeira reutilizada e a elaboração do telhado verde, que proporciona conforto e reutilização do espaço para cultivo de uma horta orgânica.

\section{ABSTRACT}

The present research aims to present the design of a prototype for shelter of large pets. We consider the physical need of the animals, compared to us, human beings, in matters of environmental comfort, allowing for improvements and adaptations in the project. In the foreground, a study and survey of sustainable materials and techniques that make the project more sustainable and feasible begins. We adopt the use of some specific materials and combine sustainable techniques such as the implementation of a green roof and study of ventilation and lighting, improving user comfort and making it sustainable. We conclude the final project for the execution of the sustainable housing, using materials such as sustainable slabs (recycled material), reused wood and the elaboration of the green roof, which provides comfort and reuse of space for growing an organic garden. 


\section{INTRODUÇÃO}

Primeiramente temos que saber que os animais, como o cachorro que é citado nesta pesquisa e se encontra sendo o enfoque, são iguais a nos seres humanos, ambos animais, por isto devemos tratá-los como tais, proporcionando cuidados básicos necessários, higiene e alimentação.

De acordo com A Declaração Universal dos Direitos dos Animais foi proclamada pela UNESCO em sessão realizada em Bruxelas - Bélgica, em 27 de janeiro de 1978 que:

- Art.1o - Todos os animais nascem iguais diante da vida e têm o mesmo direito à existência.

- Art.2o - Cada animal tem direito ao respeito. O homem, enquanto espécie animal, não pode atribuir-se o direito de exterminar outros animais ou explorá-los, violando este direito. Ele tem o dever de colocar sua consciência a serviço de outros animais. Cada animal tem o direito à consideração e à proteção do homem.

Um abrigo, como chamamos para nos seres humanos, habitação ou casa, sempre esteve presente em nosso desenvolvimento durante a história, com os outros animais, não é diferente, os mesmos também necessitam de abrigo, sendo ele um local seguro onde esteja afastado ou protegido de sol, chuva, vento e que proporcione o conforto adequado, tendo uma saúde física preservada. Ainda sobre os direitos dos animais;

- Art.5o - Cada animal pertencente a uma espécie que vive habitualmente no ambiente do homem, tem o direito de viver e crescer segundo o ritmo e as condições de vida e de liberdade que são próprias de sua espécie. Toda modificação imposta pelo homem para fins mercantis é contrária a esse direito.

A pesquisa tem por objetivo proporcionar ao animal um abrigo onde sejam priorizadas as questões relacionadas ao conforto ambiental e a sustentabilidade.

\section{FUNDAMENTAÇÃO TEÓRICA}

\subsection{Conforto do ambiente}

Como SILVA E BORMIO 2016 relata, em relação do usuário com o ambiente, destaca-se a influência que o ambiente exerce sobre o mesmo no desempenho de suas atividades, uma vez que este condiciona e interfere no comportamento, na produtividade e na saúde do usuário, seja de forma positiva ou não. Tal fato faz com que esta relação seja caracterizada por uma constante busca de uma configuração ambiental que satisfaça as necessidades físicas e psicológicas de forma a proporcionar conforto, segurança e bem-estar.
Essa configuração ambiental ou uma construção varia muito, e deve atender as necessidades particulares do uso que este terá, o tipo de usuário e as atividades que ali serão desenvolvidas, ocorrendo locais onde as preocupações com os aspectos físicos ambientais terão que ser maiores do que em outros.

\subsection{Telhado Verde}

Telhado verde é toda cobertura ou telhado, que possui uma camada de solo ou substrato e em sua superioridade uma de vegetação. Podem ser extensivos ou intensivos. Os telhados verdes extensivos são caracterizados pela alta resistência às variações pluviais e climáticas, fazendo com que não seja muito necessária à sua manutenção. Coberturas verdes extensivas possuem entre 8 e $12 \mathrm{~cm}$ de substrato, fazendo o peso do sistema variar uma média de $150 \mathrm{~kg} / \mathrm{m}^{2}$ quando saturado e não é requerido reforços significativos na estrutura de edificação (Cruz e Zanin, 2010). Telhados intensivos são elaborados em estruturas planas, não sendo possível sua instalação em ambientes inclinados devido à espessura, e precisam de cuidados especiais como, por exemplo, irrigação e nutrientes, tornando-o um sistema com custos mais elevados (MINKE, 2004). Esse tipo de telhado caracteriza-se pelo uso de plantas que demandam maior consumo de água, adubo e manutenção.

Os telhados verdes também podem ser chamados de telhados vivos, cobertura viva, cobertura vegetal, entre outros. Essas denominações são utilizadas para designar o uso de vegetação plantada sobre coberturas com impermeabilização e drenagens adequadas (GONÇALVES, 2009).

Os primeiros telhados verdes foram supostamente os famosos Jardins suspensos da babilônia, uma das sete maravilhas do mundo antigo, que foram supostamente construídas entre os séculos 800 a.C e 600 a.C (GRANT et al, 2003). No entanto o primeiro telhado verde no Brasil foi implantado em 1988 em Pedra Azul, no município de Domingos Martins (EDIMAR BINOTTI)

$O$ teto verde proporciona vantagens tanto para as pessoas como para o microclima da região onde se encontra inserido, a vegetação encontrada nessas coberturas traz equilíbrio, ou seja, uma estabilização para o clima, assim oferecem grandes benefícios para a saúde das pessoas. Estudos comprovam que morar em locais com áreas verdes melhoram as chances de ter uma vida mais saudável, ou seja, mais vegetação, mais saúde. Grandes doenças passam a ser evitadas pelo contato por menor que seja em com essas áreas, por isso é de extrema importância ter um local assim, ter mais acesso a natureza 
e aos benefícios que ela nos proporciona. Existem muitos estudos científicos a respeito desses telhados, na área de isolamento térmico, onde apresentam a redução no consumo e custo de energia, bem como redução no efeito das ilhas de calor urbano. (SANTAMOURIS et al, 2007)

Os telhados verdes também influenciam a melhoria das condições atmosféricas do ar e da temperatura, otimizando o isolamento térmico, o armazenamento de calor da edificação e o isolamento acústico. Além disso, produzem oxigênio e absorvem gás carbônico e partículas nocivas, filtram partículas de sujeira e poeira no ar, reduzem as variações de umidade no ar, protegem contra a luz solar intensa, fornecem alojamento para insetos como, por exemplo, borboletas, favorecendo a biodiversidade (MINKE, 2004).

Mais de $85 \%$ da população brasileira reside em áreas urbanas, ou seja, o processo de urbanização em território nacional efetuou-se de maneira vertiginosa. Contudo a ausência de fiscalização no andamento desse processo, bem como a falta de conhecimento, por grande parte da população, direcionado ao que se refere de conforto ambiental, causaram alterações desfavoráveis nas metrópoles assim como de cidades vizinhas (IBGE, 2008).

Um exemplo é o caso da elevação da temperatura, originando o que chamamos de ilhas de calor, e também o aumento da quantidade de veículos tendo como consequência à elevação de gás nocivo e tóxico a sociedade, criando assim o que se chama de cidade cinza. Com essas alterações foi e é inevitável o surgimento de doenças muitas vezes irreversíveis ou até fatais para as pessoas em contato extremo com esses centros urbanos. Na tentativa de reverter essa situação, surgiram Práticas de Estado eficazes direcionadas a melhoria da mobilidade urbana (criação de ciclovias), transporte público (incentivo ao deslocamento em ônibus e metro), no entanto a prática de atividades no que se refere a sustentabilidade não tem demonstrado soluções notáveis para o sistema. Telhado Verde: uma das técnicas completamente satisfatória, porém pouco utilizada no Brasil.

O uso do Telhado Verde em edifícios nas grandes cidades diminui o impacto no microclima das estruturas aumentando a umidade relativa do ar e diminuindo a temperatura média. Esse tipo de telhado também proporciona melhoria no isolamento térmico adaptado pelas camadas vegetais, gerando um ambiente interno mais confortável. O Ecotelhado, entretanto, pode ser considerado a nova geração dos telhados verdes convencionais, já que o mesmo incorpora vantagens de um jardim suspenso comum, juntamente com a captação de água da chuva, tratamento de efluente, captação de energia solar e outros benefícios. (VELÁSQUEZ, 2005).

No Brasil, passamos por diversos problemas como: racionamento de água, poluição e demanda grande de energia. Ainda não é uma a prática muito adotada no país. Infelizmente, em território nacional, a fomentação de políticas públicas pelo plano diretor quando relacionadas a sustentabilidade é pouco considerada na legislação brasileira, sendo incluída apenas no Estatuto da Cidade. Em alguns estados e cidades brasileiras, já existem projetos de lei que visam a obrigatoriedade da instalação de telhado verde em edificações habitacionais com mais de quatro andares e não habitacionais com 400 metros quadrados de área coberta. Como é o caso das cidades de Recife (PE) e João Pessoa (PB). Apesar de ser uma tendência a longo prazo, a fomentação de políticas públicas sustentáveis são de extrema importância para a sociedade nostálgica atual, pois desperta o interesse para a criação de um novo mundo. Em relação aos custos da implantação, o custo do telhado verde é apenas viável quando o uso deste já está incluso no projeto, ainda assim, o custo é alto.

\subsection{Telhado Verde $x$ Eco telhado}

O Eco telhado é um avanço do telhado verde, que inclui todos os benefícios de um jardim suspenso juntamente com um sistema de captação da água da chuva e captação de energia solar. Consiste em uma prática com um valor mais significativo, no entanto, com um resultado mais eficaz. É necessária fazer uma consulta a um especialista em instaladas de tetos verdes para melhor informação de qual tipo de telhado se adequar melhor a seu caso. Normalmente essa resposta é dada a partir da inclinação do telhado ou do clima da região aonde a edificação irá ficar. Diante da resposta do especialista, pode-se alterar o tipo de vegetação implantada.

\subsection{Materiais}

A instalação do telhado verde consiste na implantação de no máximo oito camadas, sendo: Vegetação, substrato, filtro, drenagem, proteção mecânica, membrana antirraiz, membrana a prova d'água e laje. 
Figura 01 - Componentes do telhado verde



Fonte: Alterada pelo autor, 2016.

Laje: É necessária uma laje de concreto para o sustento do telhado, considerando o peso na vegetação. Influencia também no escoamento da água. No projeto da casa do animal, a "laje" foi feita por uma placa sustentável que foi utilizada como cobertura. Membrana a prova d'água tem a função de proteger contra infiltrações, neste caso foi utilizado uma lona de plástico reutilizada, representando também a membrana antirraiz e Proteção Mecânica para Proteger as ações perfurantes das raízes, que neste caso, as hortaliças são de um porte significativo e não causam esta preocupação a construção. Para a drenagem do excesso de liquido foram utilizadas placas sustentáveis (compostas por material de reciclagem compensado) e uma camada de lona para o escoamento até um cano PVC (escoamento da agua). Para o filtro foram utilizadas pedras. Vegetação, o componente mais importante do conjunto a ser determinado, pois depende de variáveis funcionais, estéticas e climáticas. Para telhados verdes, as espécies vão das crassuláceas - armazenam água em suas suculentas folhas- às famílias das agaváceas, bromeliáceas e cactáceas, entre outras, mais conhecidas por plantas suculentas. (ALMEIDA, 2008). Foram utilizadas hortaliças como alecrim, cebolinhas, alface entre outras para o cultivo e uso pessoal.

\section{METODOLOGIA}

O protótipo foi divido em três etapas, projeto arquitetônico, executivo e construção, com algumas adaptações finais.

O projeto teve início com o desenvolvimento do projeto arquitetônico da "casinha" sustentável e o desenvolvimento do desenho em 3D, com isto, começaram a ser feito o levantamento dos materiais sustentáveis e com a finalização do projeto executivo deu-se início a execução in loco. Inicialmente foram feitos os desenhos com medidas orientadas pelo projeto nas placas sustentáveis, para o fechamento da construção da casa, em seguida, foram realizados os cortes e as aberturas para as janelas e entrada do animal.

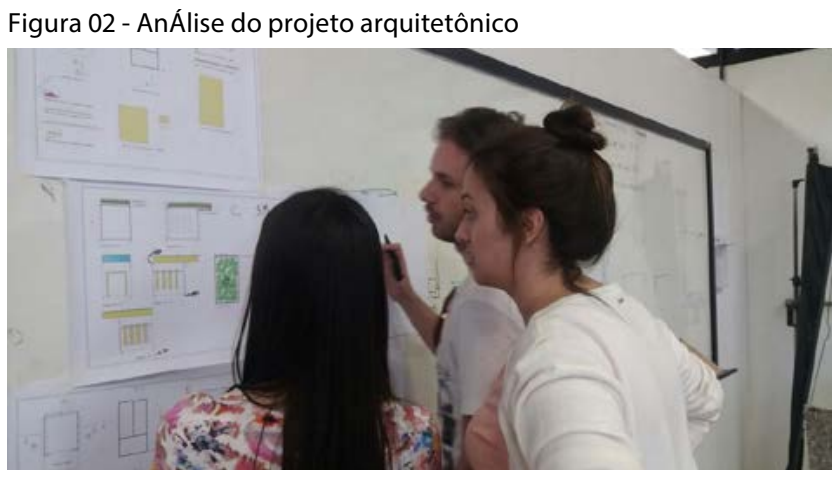

Fonte: Autor, 2016

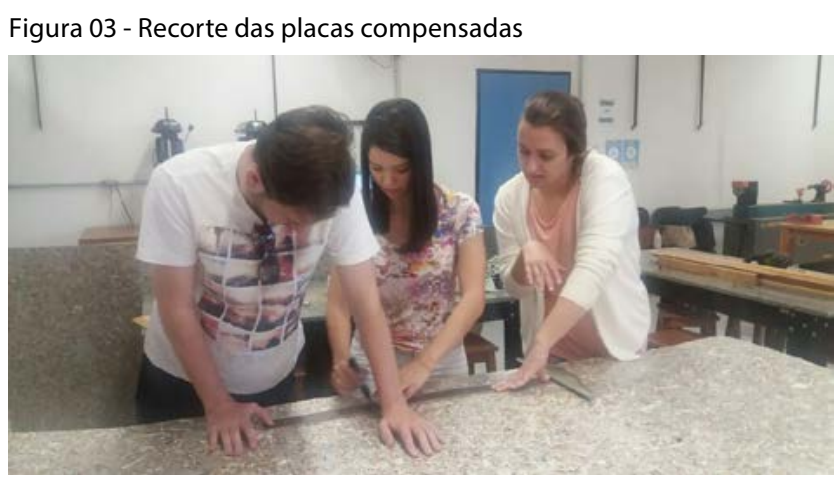

Fonte: Autor, 2016.

Figura 04 - Recorte das madeiras para a estrutura

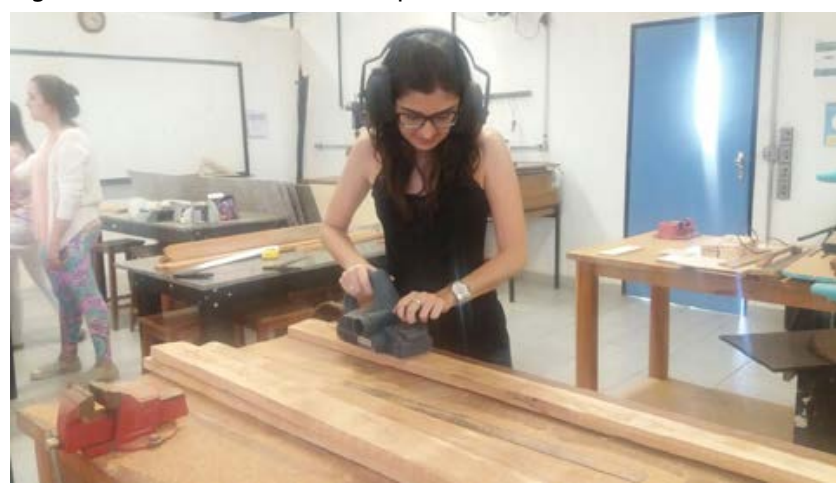

Fonte: Autor, 2016

Para estruturar a casinha, começamos o recorte de vigas e pilares de madeira, houveram algumas alterações durante a execução, reformulando ideias para a estrutura, que foram revistas na etapa da construção. Com a estrutura pronta e as placas de fechamento finalizadas, a casa do animal foi tomando forma e dando início ao preparativo para o telhado verde, com o mesmo esquema de fechamento, as placas sustentáveis, que também utilizamos para construir as platibandas e o forro da construção. 
Figura 05 - Finalização do fechamento da construção

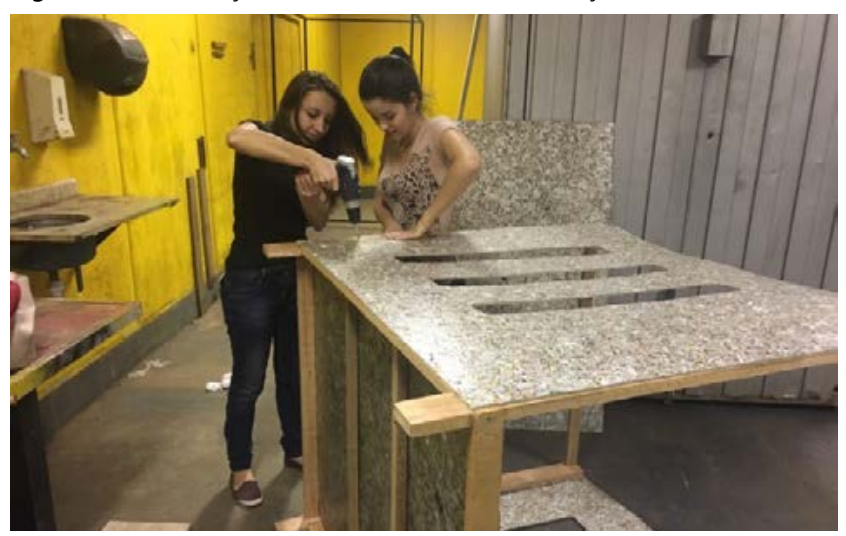

Fonte: Autor, 2016.

Figura 06 - Finalização da estrutura para receber o telhado

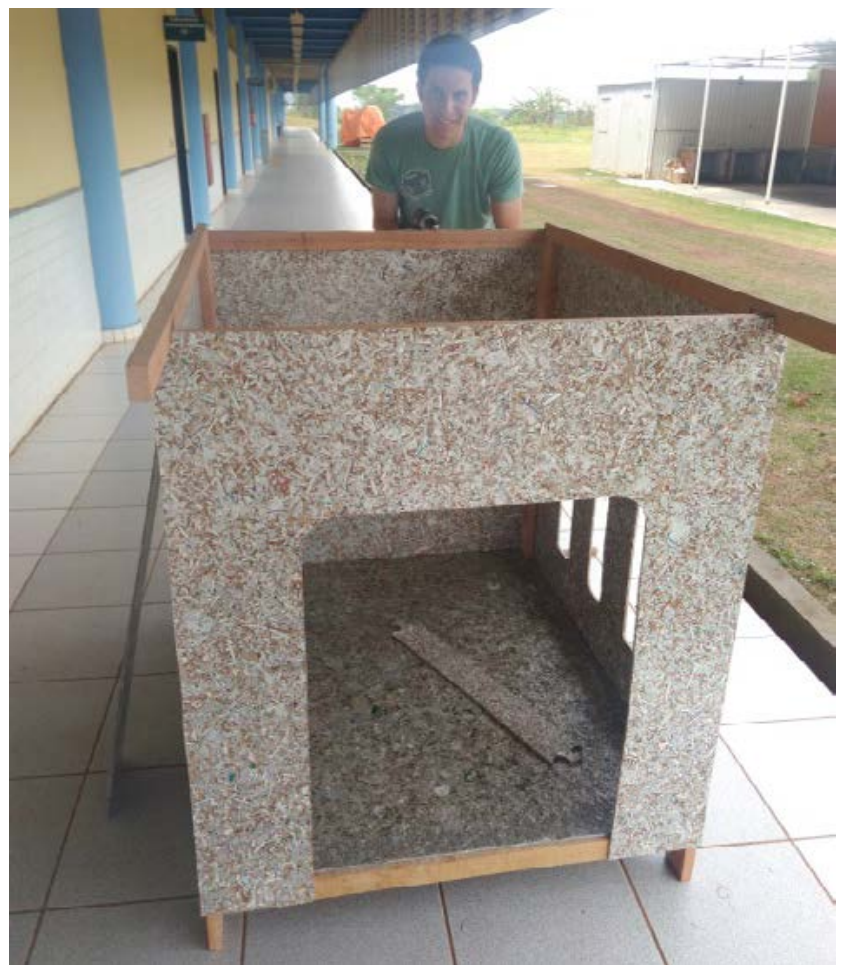

Fonte: Autor, 2016.

Figura 07 - Telhado verde com as camadas adequadas instalado

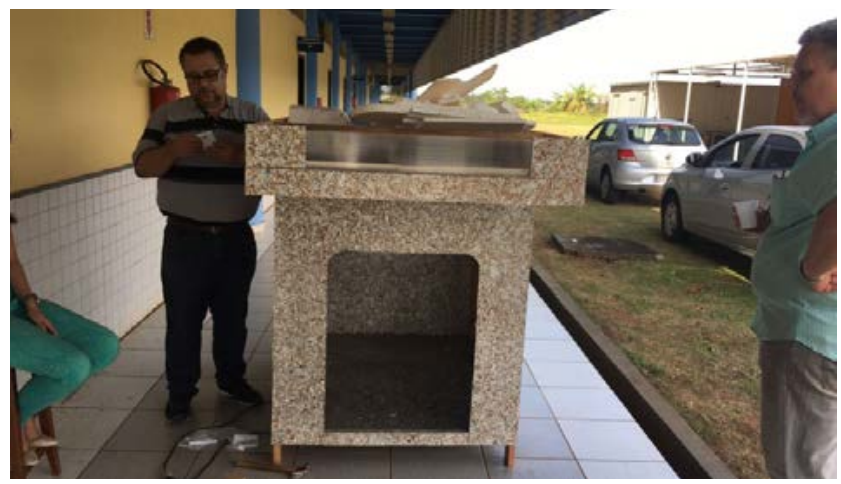

Fonte: Autor, 2016.
Figura 08 - Finalização do projeto

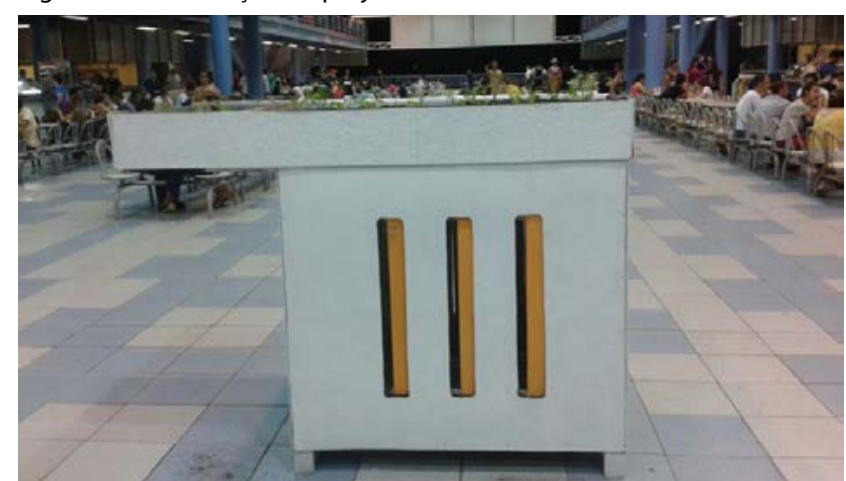

Fonte: Autor, 2016

Figura 09 - Aplicação de hortaliças

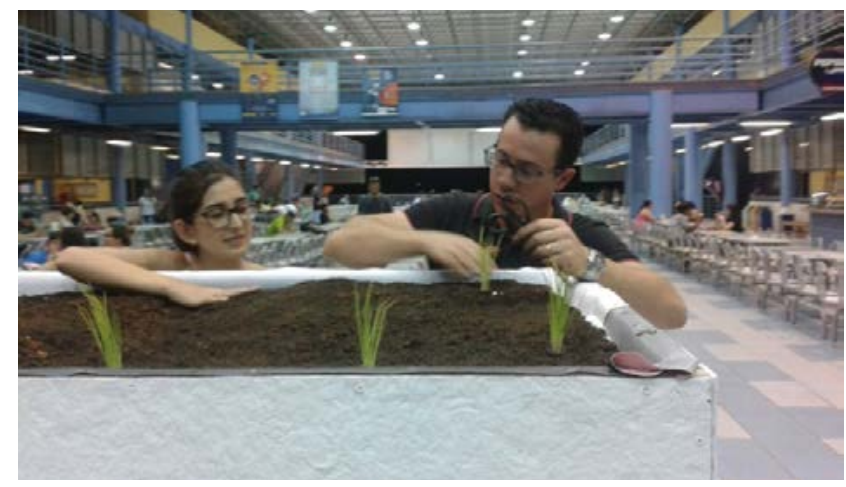

Fonte: Autor, 2016

Constituiu-se em uma estrutura de madeira independente, se tornando um telhado removível, e com as camadas adequadas, com os materiais reutilizados, e com uma captação de água por meio de canos de PVC ao fundo da casa, na elevação posterior.

As janelas foram pensadas para o conforto do usuário, sendo possível a troca de calor e ventilação interna e externa e possibilitando a entrada de luz que em muitos outros casos em residências de animais, não possuem nenhuma entrada de luz ao não ser a única abertura que é utilizada pelo animal como entrada e saída.

\section{CONCLUSÃO}

Como conclusão deste protótipo, a análise feita em relação aos materiais utilizados foi satisfatória. Durante a construção foram adaptados alguns detalhes, porém, os cálculos foram adequados desde o início do projeto sustentando o telhado e todos os seu componentes e vegetação, proporcionando ainda o cultivo de uma horta orgânica.

Foi testado uma sobrecarga de $80 \mathrm{~kg}$ na fase final e a casinha continuou sob as expectativas desde o início, sustentando este peso que seria em média de um animal 
doméstico (cachorro) de grande porte, com conforto adequado, fácil reprodução e com materiais de fácil acesso e acima de tudo sustentáveis.

Figura 10 - Exposição da casa

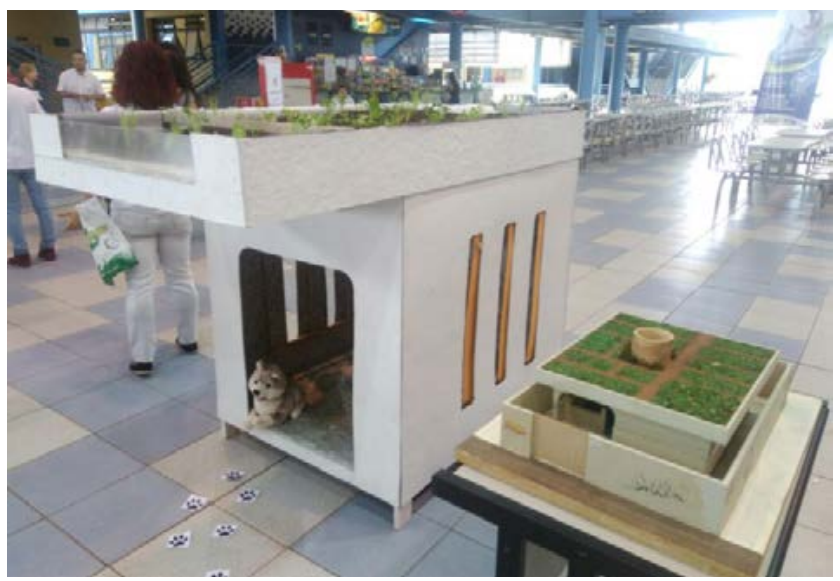

Fonte: Autor,2016.

Figura 11 - Perspectiva digital da construção

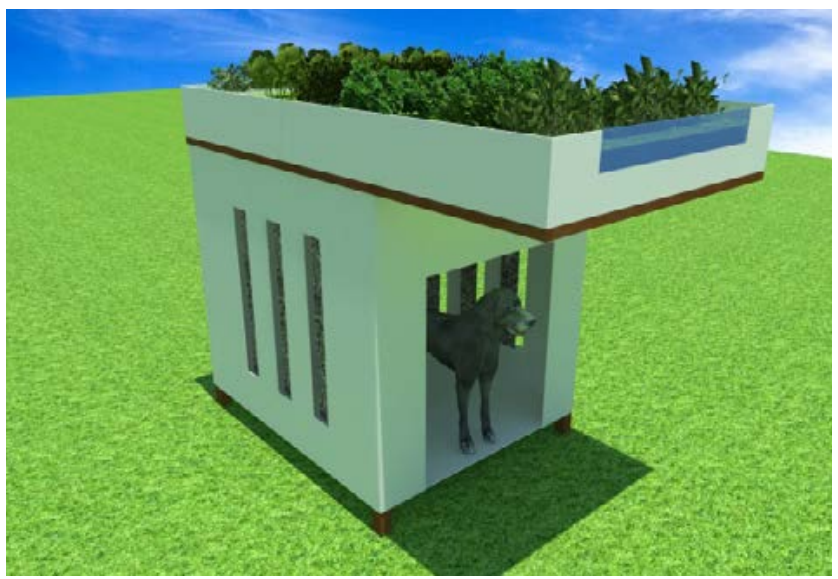

Fonte: Autor, 2016

Figura 12 - Vista interna da construção

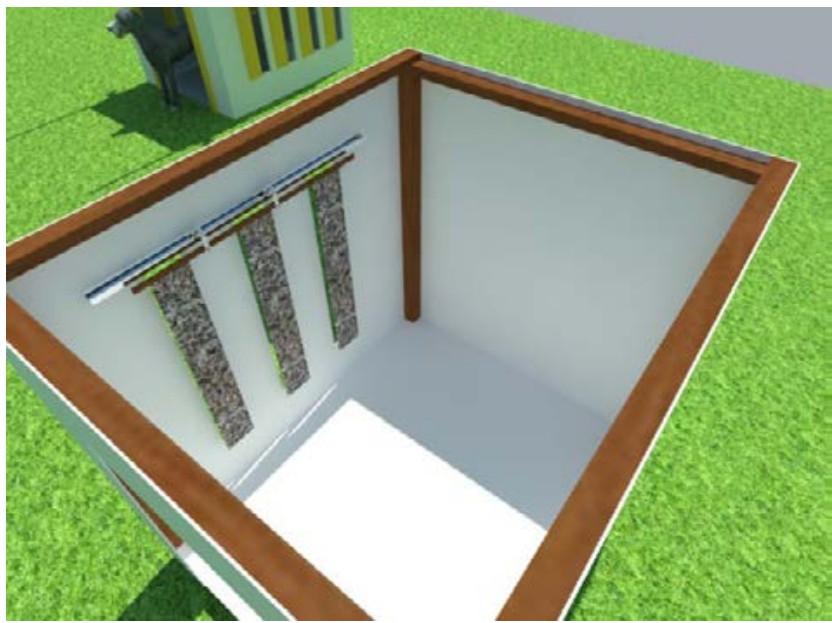

Fonte: Autor, 2016

\section{REFERÊNCIAS}

BALDESSAR, S. M. N. Telhado Verde e sua contribuição na redução da vazão da agua pluvial escoada. 2012 125 f. Monografia (Especialização) - Curso de Construção Civil, Universidade Federal do Paraná, Curitiba, 2012.

HENEINE, M. C. A. S. Cobertura Verde. 2008. 49 f. Monografia (Especialização) - Curso de Construção Civil, Universidade Federal de Minas Gerais, Belo Horizonte, 2008.

MARY, W.; SILVA, L. P.; MORAES, M. F. Telhados Verdes: Ferramenta potencial para geração de renda em áreas de fragilidade social.. 2008. 17 f. Monografia (Especialização)- Curso de Arquitetura e Urbanismo, Universidade Federal Rural do Rio de Janeiro, Curitiba, 2008.

SILVA, N. C. Telhado Verde: Sistema Construtivo de Maior Eficiência e menor impacto ambiental. 2011. $63 \mathrm{f}$. Monografia (Especialização) - Curso de Construção Civil, Universidade Federal de Minas Gerais, Belo Horizonte, 2011.

SILVA, V. L. A.; BORMIO, M. F. A importância do uso ergonômico da cor na interface ambiente $x$ usuário p. 666-673 In: $1^{\circ}$ Congresso Internacional de Ergonomia Aplicada [Blucher Engineering Proceedings, v.3 n.3] São Paulo: Blucher, 2016. ISSN 2357-7592, DOI 10.5151/ engpro-conaerg2016-7828

THOMAZELLI, L. M. (Org.). Telhado verde: o telhado ecológico: um modelo prático, sustentável e de baixo custo.. Telhado Verde, São Paulo, p.1-21, 2013. 